MAGDALENA CATTAN LAVIN

DEPARTAMENTO DE DISEÑO

FACULTAD DE ARQUITECTURA Y URBANISMO

UNIVERSIDAD DE CHILE

SANTIAGo, Chile

MCATTAN@UCHILEFAU.CL

PHD CANDIDATE

EDINBURGH COLLEGE OF ART.

THE UNIVERSITY OF EDINBURGH

1. Sitio web https://www.gt2P.com/

\section{Entrevista a Guillermo Parada, socio y fundador de gt2P - Great things to People}

Interview to Guillermo Parada, partner and

founder of gt $2 P$ - Great Things to People

El grupo gt2P es un estudio de Diseño, Arte público y Arquitectura, cuyas propuestas conjugan el lenguaje digital del diseño paramétrico con la experimentación práctica de materiales y procesos manuales. Desde 2014, las obras de gt2 $\mathrm{P}$ han sido exhibidas y reconocidas internacionalmente, incluyendo el Museum of Art and Design (MAD), Met Museum, Design Museum London y Friedman Benda Gallery. El estudio está compuesto por los arquitectos Tamara Pérez, Sebastián Rosas, Víctor Imperiale, Eduardo Arancibia y Guillermo Parada.

En esta entrevista, conversamos con Guillermo Parada sobre cómo se dio la virtuosa relación entre el quehacer desde el diseño paramétrico con los procesos manuales y artesanales, que se ha transformado en elemento característico de las propuestas de este estudio. Además, hablamos de la colaboración con centros artesanales tradicionales -comunidades en torno a una técnica- y cuán significativo sería para ellos ampliar e internacionalizar sus canales de mediación y comercialización para subsistir en el tiempo fomentando su quehacer como motor de desarrollo local ${ }^{1}$. 
Para comenzar, quisiera preguntarte ¿cómo definirían ustedes, en su práctica profesional, la relación de lo hecho a mano con lo digital? Porque, sin duda, esta mixtura se ha transformado en un elemento característico de varias de sus obras y productos.

Es mejor contarte cómo comenzó todo. Con Tamara nos conocimos en el pregrado y con Sebastián en el Magíster de Arquitectura de la Universidad Católica. Ahí descubrimos que teníamos intereses comunes sobre el diseño paramétrico y la fabricación digital, pero además teníamos la inquietud de hacer, que las cosas se sistematizaran y fabricaran. Al inicio, partimos siendo muy "extremistas" del diseño paramétrico, creíamos que todo iba a ser construido por robots, un pensamiento bien ingenuo en ese sentido, porque cuando empezamos a construir nuestras cosas, nos dimos cuenta de que había un sin fin de procesos manuales detrás.

Uno de los primeros objetos con el que partimos fue un simple florero que fabricamos en colaboración con unos ceramistas en Quinta Normal. La persona que hacía los moldes era ciego, él tocaba las cosas y luego reproducía los moldes -su relación con los objetos era en base a puro tacto-. Entonces, al final, esperábamos que el molde saliera tal cual como nuestra impresión 3D, o como el paquetizado láser que habíamos hecho, pero era imposible. Después, el florero se fue a la quema y el esmalte salió con los hoyitos, no liso como lo habíamos proyectado y decíamos “ies que no puede ser!". Luego, en otro proyecto, nos dimos cuenta de que si usábamos paneles de terciado de diferentes proveedores había diferencias en el resultado. Entonces empezamos a darnos cuenta de que había otras variables en el problema de diseño que aparentemente era perfecto en el mundo del computador, pero una vez en el mundo real aparecían otro tipo de desafíos que son parte de los procesos manuales y tienen que ver los materiales, como con las temperaturas dentro del horno. Tiene que ver con un montón de elementos que no tienen cabida en el mundo digital, sin embargo, hasta ese momento, aún no nos dábamos cuenta de que ese era nuestro valor. Fue cuando hicimos nuestra primera exhibición en el Salón Satélite de Milán, donde dijimos "aquí está nuestro cruce y nuestro valor". Esta cuestión que estamos peleando a regañadientes debiéramos ocuparla a favor nuestro y potenciar la mezcla entre estos dos tipos de conocimientos: el conocimiento manual, más empírico y basado en la experiencia, junto con el conocimiento global de diseño paramétrico, que es lo que estudian en todo el mundo sin importar el contexto. Entonces, en nuestro proceso no fue una decisión deliberada que hayamos querido entrar en el mundo del hacer manual, fue una situación que se dio en la práctica de manera súper orgánica. Fue como que tuvimos que salir de Chile, dar una vuelta, para darnos cuenta.

\section{De que ahí estaba el valor y la propuesta...}

Claramente, y ahí nos metimos de cabeza a producir una colección que se llamó "Digital Crafting" o artesanías digitales. Al año siguiente, expusimos eso nuevamente en Milán y tuvimos un artículo pequeño en la revista FRAME. Con esto, logramos poner una bandera de un discurso propio desde nuestro país, el que hablara de un cruce desde una tecnología que era global y relativamente homogénea en todo el mundo, con algo de nuestros recursos locales, sin borrar el pasado, sino que mezclándolo con estas nuevas tecnologías.

Aquí aparece para nosotros el primer enfoque entre estas dos maneras de hacer que en un principio veíamos súper disímiles e incompatibles, pero que 
después nos dimos cuenta que ahí estaba todo el valor de nuestro estudio, transmitir un conocimiento a las personas con las que trabajamos y que ellos nos transmitan conocimiento de vuelta a nosotros. De esta manera, podemos generar productos únicos, series cortas y entender de que el mundo más manual no necesariamente tiene ir al mismo mercado a competir con la producción en masa.

\section{Claro, se generan nuevos espacios para visibilizar estos objetos y hay} otras audiencias que tienen ese interés.

Exacto y existen esos canales en el mundo. Por ejemplo, el mercado de la artesanía crece todos los años un $8 \%$. Definitivamente hay un mercado interesado en eso. Este es un potencial que deberíamos asumir y está en crecimiento. ¡Hagamos algo con eso!

Centrándonos entonces ahora en la artesanía y el imaginario de la artesanía tradicional en Chile, podemos ver en algunos de sus proyectos una referencia evidente, como por ejemplo en "Losing my America", (parte de la exhibición "New Territories: Laboratories for Design, Craft and Art in Latin America" 2014 en MAD), donde hay un repensamiento de piezas tradicionales, haciendo visible un encuentro con las técnicas digitales. A partir de ese proyecto y sus motivaciones ¿cuáles son los elementos de las artesanías tradicionales y oficios propios de Chile que GT2P toma como inspiración para sus propuestas ¿Tiene que ver con la materialidad de nuestro territorio, la plástica o los procesos?

En un momento en la oficina empezamos a cuestionar todo lo digital y "Losing my America" es una visión súper pesimista sobre ello. Hay mucha gente que lo ha interpretado como que nuestro discurso era: "el computador es mejor, parametricemos todo", incluso condenando el proyecto. Pero lo que queríamos hacer era justamente lo contrario. Teníamos un set de piezas icónicas de artesanía donde dejamos una sección hecha manualmente y otra se empezaba a digitalizar, pero era justamente por decir "somos diferentes, pero nos estamos poniendo igual". Entonces, aprovechamos ese discurso y el lugar donde íbamos a exhibir, que era el Museum of Art and Design de Nueva York que tenía a Glen Adamson como director, y en esa instancia mostramos la pieza y también cómo esa pieza se hizo. La idea era transformar esa idea pesimista en una invitación para la gente que iba a visitar -supuestamente diseñadores, arquitectos y artistas- dijera: "mira, en Sudamérica tenemos mucha diversidad" y sintieran la inquietud de viajar y trabajar con ello. Y se logró el objetivo, en el sentido de que ya hemos tenido dos visitas importantes; por ejemplo, los hermanos Campana vinieron a trabajar a Santa Cruz y también tuvimos la visita de un par de curadores de Diseño, incluyendo uno del MET MUseum. Fue como un proyecto de promoción de las artesanías de Sudamérica.

Los centros artesanales que identificamos y con los que trabajamos, más que generar una pieza icónica, tienen la condición de generar comunidad. Al principio, muchos nos decían "los artesanos no van a querer intervenir sus piezas", pero fue lo contrario, la mayoría de ellos dio pie para que hiciéramos lo que quisiéramos: innovar o usar procesos diferentes. Ellos entendían que el valor de su práctica está en otras cosas, en que pueden alimentar a su familia, generar una junta de vecinos donde la comunidad se reúne a conversar, en la posibilidad de generar comunidad. Entonces, si a una de sus piezas se le cambiaba la forma, no era lo más importante. De esta manera, combatíamos la idea de 
la cosificación del ícono como único valor patrimonizable y proponíamos que lo patrimonial es la noción de que una técnica genera comunidad.

Claro, muchas veces el discurso de salvaguarda da la impresión de que la artesanía debiera quedarse bajo una cúpula de vidrio. Pero, al conversar con los artesanos, es real que varios de ellos quieren probar cosas nuevas y salir de la repetición de sus piezas. Muchas veces el problema es el acceso a las nuevas herramientas y tecnologías, entonces pienso que ahí es cuando estas colaboraciones se vuelven interesantes y relevantes, lo importante es que sean siempre balanceadas.

De hecho, muchas veces el contacto por email se hacía a través de los nietos de los artesanos, que son rápidos con la tecnología. Los más jóvenes tienen la posibilidad de integrar el conocimiento de estas herramientas fácilmente, muchas veces en sus colegios. Ese conocimiento abriría nuevas posibilidades para los artesanos, por ejemplo trabajar con gente en otras partes del mundo, diseñadores de otros lados, pero produciendo aquí. No se trata de ver estas tecnologías como métodos sustitutivos, sino conectivos con el mundo. Esa es nuestra visión y es una de las ideas que tenemos para un siguiente proyecto que se llama "Hecho por Chile", que tiene que ver con desarrollar centros de creación en las comunidades artesanales, para amplificar el modelo de negocios de los artesanos. Con esto me refiero a que este centro tenga un restaurante y un hotel, si es que son lugares alejados de las ciudades grandes; que pueda tener una galería de exhibición y un espacio donde se pueda enseñar la técnica; que tenga un lugar para crear nuevos productos y nuevas empresas, spin-off dentro de este mismo centro de creación.

Mientras hacíamos el proyecto "Losing my America", aparece el "Caterany Pottery Printer", que tenía como motivación explicarles a los artesanos qué era el diseño paramétrico. ¿Cómo explicamos de manera simple qué es el diseño paramétrico sin un computador de por medio? Así aparece este dispositivo, que le hace un "chiste" a la impresora 3D, al ser un aparato de madera y tela sin componentes electrónicos.

En ese momento no le tomábamos el peso a los que habíamos creado, pero sin duda este proyecto nos dio la orientación de que nuestro trabajo es más "paramétrico" que "digital". De alguna manera, fue una respuesta para poder transmitir el conocimiento a alguien.

Entonces cuando me preguntas en qué nos inspiramos, es difícil, porque no es solo un punto. De partida, somos un equipo, entonces hay varios intereses que confluyen. Estamos convencidos de que las grandes ideas se hacen a partir de muchas microideas y que cuando se articulan aparece un gran proyecto.

Respecto a su experiencia de trabajar con las comunidades de artesanos, ¿crees que hay un futuro para las artesanías tradicionales al relacionarse con las nuevas tecnologías?

Yo creo que sí o sí tienen que converger. Es algo que veo más orgánico, cómo las herramientas se van incorporando en la práctica a cada comunidad e individuo. A nosotros nos gusta mucho la definición de artesanía que arma Richard Sennett respecto de los instrumentos y las herramientas, donde dice que los artesanos son los que modifican un proceso a través de la generación de sus herramientas e instrumentos.

Entonces, creo que es algo mucho más orgánico que decir que se debe “imponer" una manera de hacer. También es necesario manejar un computador o te- 
léfono que les permita manejar su empresa y comunicarse con el mundo para hacer canales de venta. No por un tema de imposición, sino que es parte de los tiempos. Para las nuevas generaciones también es interesante aprender cosas que son diferentes a las que aprendieron sus abuelos o sus padres y pueden decir "estoy aportando con esto nuevo que aprendi". Nosotros sentimos que en las herramientas hay conocimiento, si no haces no aprendes, te pierdes la mitad de la historia, todo queda en pura especulación. Siempre que hay una herramienta nueva, hay una posibilidad nueva. Lógicamente hay afinidades de ciertas comunidades y sus prácticas con ciertas herramientas, pero, en resumen, si la pregunta es si debieran contactarse, nosotros creemos que sí. Por ejemplo, están los comentarios de que cuando llegó el torno alfarero destruyó Pomaire... yo no lo creo. Creo que las destrucciones tienen que ver con la insistencia de apuntar a los mismos mercados. Si voy a la feria de la Artesanía de la Católica y ves piezas de greda de $\$ 3.000$ y otras de $\$ 300.000$, dices "cómo va a ser tanta la diferencia de precio". Si generas esa distorsión de mercado, obviamente algunos van a quedar rezagados. Entonces, creo que esas destrucciones no pasan por la incorporación de tecnologías, sino que por abrir nuevos mercados. En el caso del torno, este redujo tiempos de producción y generó producción en masa en esa localidad, pero el alfarero que se demoraba mucho más tiempo en algo y que podía generar objetos muchos más complejos, debería haber sido dirigido a otro mercado, a un mercado que estuviera dispuesto a pagar eso y no competir en el mismo canal. Por eso creo que el éxito está en encontrar diferentes canales, y en el mundo sí existen, nos hemos dado cuenta. Lo mismo se nota en Europa...

Claro, lo primero que llama la atención en Europa es cómo se entiende la noción de "craft" en contraposición a la que se tiene en Latinoamérica. Funcionan en medios diferentes, el valor que tienen los oficios artesanales/manuales es muy diferente. Por ejemplo, se sigue enseñando cerámica, orfebrería, vidrio y textiles en la universidad, es decir, se entiende como un conocimiento formal, validado. Entonces uno ve esa brecha con el escenario en Chile. Quizás, dentro de todos los otros factores puede ser que no hay acceso a otros canales de visibilización, o bien, hay desconocimiento de ellos. En ese sentido, la iniciativa de llevar creaciones de artesanos y artistas chilenos a la bienal Révélation, en París, marca un precedente, ya que es un gran avance. Quería volver ahora al tema del trabajo conjunto con artesanos. En este contexto, ¿cómo ves los procesos de colaboración entre equipos como ustedes y las comunidades? ¿crees que realmente se pueden dar colaboraciones balanceadas donde todos participan en pos de una idea común o crees que siempre habrá un aspecto asimétrico en estas iniciativas? Si por asimétrico te refieres a que el artesano sea solo productor en algunos proyectos, es algo que ni siquiera me lo cuestionaría, pues hay proyectos y proyectos. Tengo un ejemplo sobre una idea para el Cooper Hewitt Museum que finalmente no se realizó. Encontramos un artesano mexicano que hacía unos alebrijes muy bonitos. Nuestra idea era crear un enjambre de alebrijes escapando del museo y que uno atravesara un vidrio. En ese momento queríamos usar el mismo pajarito, exactamente el mismo hecho por el artesano, entonces lo único que estábamos haciendo era articular el enjambre, pero la producción artística de cada uno de los elementos iba a ser hecha por el artesano. En cambio, otro proyecto con Víctor San Martín, para hacer vasijas, 
nosotros mandábamos el diseño y él las producía.

Entonces para ustedes es un acuerdo que se habla al inicio, al discutir el proyecto con el artesano.

Sí, de hecho, hablábamos con un amigo portugués sobre este tema, Frederico Duarte, y se nos ocurría que una de las ideas, si se implementa el "Hecho por Chile", sería que los mismos artesanos generaran sus propias empresas y pagaran un fee a diseñadores para su asesoría y luego ellos producen el resultado. Hacer el inicio de la historia de las empresas italianas, pero en Chile, porque las empresas italianas comenzaron como talleres muy artesanales, de hecho, muchas lo siguen siendo, pero tomaron las riendas transformándose en empresa y subcontratando diseño. Entonces, en ese contexto, siento que no es tema, ya que entrampa muchas cosas. Hay artesanos que dicen "no me interesa ir de socio, prefiero que me pagues mi producción y listo", pero hay otros como Juanita Muñoz de Santa Cruz que tiene visión de negocios y, si fuera por ella, tendría la empresa y contrataría los servicios de diseñadores. Finalmente, son acuerdos entre personas y que se requiere en proyectos específicos. Es un tema para observar caso a caso.

Pasando a otro tema y para ir cerrando la entrevista, me gustaría que nos contaras sobre los aspectos de mediación, visibilización y difusión de sus proyectos, que ha pasado desde desarrollar proyectos experimentales pequeños a mostrar sus obras en galerías y museos internacionales. ¿Cómo fue este camino? ¿era una meta del estudio o fue un proceso más orgánico de encontrarse con los canales adecuados para la internacionalización? ¿cómo impacta en su trabajo?

Esto nuevamente ha sido una evolución natural del estudio, donde aprendimos mucho haciendo este tour de exhibiciones y ferias de Diseño en Milán, Londres, Nueva York, Köln, Suecia, que fueron como nuestros magísteres en Diseño. Ahí aprendimos dónde podíamos generar ingresos para poder vivir del Diseño. Por ejemplo, ganar vendiendo productos para una gran marca era absurdo. Nosotros diseñamos unas piezas de cerámica, "Tarrugao”, que las vende Capellini Design y ellos lo producen con una empresa en Inglaterra que se llama 1882 y anualmente recibimos en royalties €25 por ello, jes absurdo! Entonces para vivir del Diseño con royalties tienes que tener 200 productos andando en diferentes marcas. Es imposible.

Todo cambió cuando nos invitaron al MAD (Museum of Art and Design) a exponer, la curadora jefe en ese momento, Lowery Sims, conocía a Marc Benda de Friedman Benda Gallery y le presentó nuestro trabajo. En ese momento estábamos exhibiendo el "Catenary Pottery Printer", "Losing my America” y las luminarias que incorporaban el punto de lava refundido. Luego de ver la muestra, él nos dijo que le propusiéramos algo para su galería y no lo podíamos creer. Ahí descubrimos el mercado de las galerías y que nuestros productos, al ser más experimentales, tenían la posibilidad de meterse en ese circuito. La gracia de trabajar con la galería es que podemos mantener económicamente el estudio de Diseño, el equipo e insumos, la habilitación completa del Lava-Lab. Además te da credibilidad, la gente le presta más atención a tus propuestas más arriesgadas, a las ideas y discursos.

También queríamos intervenir espacio público. Entonces, cuando presentamos en Friedman teníamos una banca -la banca suple- que estaba com- 
pletamente sobre escalada para el lugar, pero el Design Museum se interesó y la adquirió para ser usada e instalada en los jardines exteriores del museo. Esta ha sido entonces una manera de hacernos masivos y, una vez más, no habría sido posible sin haber estado antes en los museos y galerías, que son instituciones que te dan credibilidad. Por ejemplo, ahora se han abierto posibilidades para "Hecho por Chile", las que no se habrían dado si no fuera justamente por nuestra presencia internacional.

En síntesis, lo más importante son las posibilidades que este proceso de internacionalización nos ha entregado y esto sí fue una decisión consciente. Nosotros teníamos que salir, porque en Chile no hay mercado para el Diseño.

\section{¿Y mercado para la artesanía?}

Si hacemos cosas con artesanía hay que exportar, porque no se puede pretender vivir del mercado nacional. Por eso planteamos que, si existe esta red de comunidades artesanales, hay que diversificar la oferta, por eso la idea de que aparezca el hotel, el restaurante, que se pueda transformar en taller y los artesanos puedan generar ingresos por enseñar. Sacar el máximo provecho a esa técnica, para que se transforme en real motor de desarrollo local.

Julio 2019. 